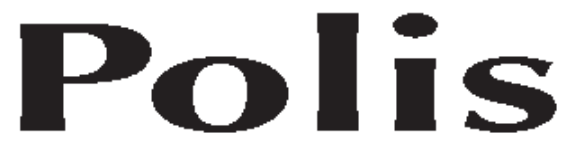

\title{
Hacia un nuevo pensamiento integracionista latinoamericano: aproximación a una lectura de segundo orden*
}

\author{
Sergio González Miranda** \\ Cristián Ovando Santana***
}

Resumen: Este artículo analiza el problema de la integración latinoamericana, que ha sido abordado a lo largo de dos siglos por distintas generaciones de pensadores, sean éstos intelectuales o políticos, generando un rico pensamiento que tiene un valor en si mismo. Sin embargo, el proyecto político no ha podido concluirse. Enfrentado además este pensamiento (desde 1989 en adelante) a una realidad internacional mucho más compleja, surge la pregunta por su vigencia. Se propone aquí una re-lectura de dicho pensamiento latinoamericano con arreglo a las corrientes intelectuales y disciplinarias que han emergido en (o sobre) América Latina en las últimas décadas.

Ya iniciado el siglo XXI nos encontramos con un gran volumen de obras de pensadores integracionistas elaborados en la región, pero que no son equivalentes a la realidad socio-política de América Latina. Si bien han surgido acuerdos políticos, donde los más relevantes han sido ALALC, Pacto Andino, ALADI, MERCOSUR, UNASUR, éstos no han podido transformarse en una comunidad continental efectiva.

Esta contribución se adentra en la búsqueda de un nuevo pensamiento latinoamericano, que considere los actuales fenómenos internos de la región (producto de los procesos globalizadores y descentralizadores) y las nuevas formas de actuación internacional.

Palabras clave: Integración latinoamericana, relaciones internacionales, fronteras, pensamiento latinoamericano.

\section{Towards a new latinamerican integrationist thought: an aproach to a second level reading}

Abstract: This article analyzes the problem of Latin-American integration that has been raised throughout two centuries by different generations of thinkers, either intellectuals or politicians, creating a rich thought that is valuable by itself. However, the political project has not been able to be completed. Besides, facing this thought (since 1989 onwards)

\footnotetext{
* Este artículo es resultado parcial del proyecto de investigación Fondecyt 1070032. También es resultado del Proyecto "Pensamiento integracionista y transformaciones sociopolíticas en América Latina". DGI/UNAP ${ }^{* *}$ Universidad Arturo Prat, Iquique, Chile. Email: sgonzale@unap.cl

*** Universidad Arturo Prat, Iquique, Chile. Email: covando@unap.cl 
to an international reality even more complex, a question comes up due to its relevance. A re-reading is suggested about Latin-American thought in connection to the intellectual and disciplinary trends that have surfaced in (or about) Latin America in the last decades.

Once the $20^{\text {th }}$ century starts, we find a great volume of integrational thinker's works drawn up in the region, but which are not equivalent to the socio-political Latin American reality. Although political agreements have come up in which the most relevant have been ALALC, PACTO ANDINO, ALADI, MERCOSUR, UNASUR, these have not been able to turn into an effective continental community.

This contribution is studied thoroughly in the search for a new Latin American thought that takes into account the current internal phenomenon in the region (result of the comprehensive and decentralized processes) and the new ways of international action.

Key words: Latin American integration, foreign affairs, borders, latinamerican thought

\section{Introducción}

Integración ha sido la palabra clave en los últimos doscientos años de un iniciado pero nunca acabado proyecto político continental, el que ha tenido períodos de mayor o menor impulso, donde los discursos integracionistas a veces expresan una realidad o necesidad supuestamente ineludible, y otras, un mundo propio, plenamente literario. Edmundo Heredia señala que "usamos el concepto de integración porque es el actualmente en uso y representa ahora la persistencia de una idea que se originó y perduró, con distintos nombres pero siempre con una suerte menguada, a lo largo de la historia latinoamericana". (1999:28) Efectivamente, la integración latinoamericana ha sido como el mito de Sísifo, un eterno comenzar en busca de la cima de una montaña inalcanzable. Cabe preguntarse si no es el momento de cuestionar el concepto, o definitivamente realizar una nueva definición de la integración latinoamericana a partir de la deconstrucción del discurso.

Leopoldo Zea, uno de los más prestigiosos integracionistas, plantea que en 1989 "culmina y termina la historia iniciada en 1492" (1992:15). Se refería a el término de la Guerra Fría, y viendo el triunfo de la economía de mercado bajo la Globalización pensaba que América Latina tenía una oportunidad como productor y consumidor, porque "la globalización que obliga a compartir el desarrollo alcanzado o por alcanzar para que éste no se detenga y siga creciendo" (1992:17) No sin temores, por cierto, puesto que percibía la "atomización en la globalización" y la "resistencia a reconocer la existencia de un mundo multirracial y multicultural", y nos señalaba que "los pueblos de esta nuestra región en América, integrados por su propio origen y desarrollo, podrán participar en este mundo sin por ello renunciar a lo que son". (1992:20) Cabe la pregunta si en 1989 cayó algo más que 
el muro de Berlín, si en América Latina también se cerró un ciclo de una perspectiva basada en una integración y modernidad continental. La globalización, entonces, además de generar lo que sospechaba Leopoldo Zea pudo también modificar el contexto social a escala internacional, que obliga a una relectura del discurso integracionista latinoamericano que, por cierto, no ha perdido relevancia histórica pero puede, sin embargo, haber perdido vigencia práctica. Sería preciso enfrentar el pensamiento latinoamericano no sólo con la realidad actual, sino con las teorías en relaciones internacionales o de las fronteras actualmente en competencia.

Seis años antes de la caída del muro de Berlín, otro gran latinoamericanista e integracionista, Felipe Herrera Lane, a propósito de cumplirse en 1983 doscientos años del nacimiento de Simón Bolívar, señalaba que su "trayectoria, ideario y proyección histórica, surgen con plena vigencia en el contexto de la América Latina de hoy, caracterizada por desafíos ya tradicionales, y por otros, propios de esta nueva etapa del acontecer humano, inesperados y de compleja respuesta..." (1986:193). Este dilema entre seguir o desear que sigan vigentes los idearios de próceres y pensadores integracionistas latinoamericanos y los desafíos de los nuevos fenómenos que enfrenta América Latina, es la tensión esencial de un cambio en el paradigma integracionista latinoamericano. Con posterioridad a 1989 se puede observar una inflexión en los procesos económicos y sociales en América Latina (y en el mundo) que los pensadores integracionistas no pudieron imaginar, como la escala de las migraciones, la problemática energética, la emergencia de los poderes locales, la internacionalización de la economía y las tecnologías, la globalización, etc., y sobre todo la pérdida de poder de los estados nacionales.

Eduardo Devés-Valdés respecto de la integración Latinoamericana se pregunta: ¿por qué se avanza tan poco en un asunto en el que aparentemente hay tanto acuerdo, casi desde Bolívar para acá? Su respuesta es descarnada, nos dice que "la alta legitimidad que tiene el tema de la integración otorga prestigio a quien lo utiliza, por lo que en demasiadas ocasiones no se aborda el tema para pensar el problema, sino para obtener legitimidad". (2007:19) Ha surgido en estos dos siglos un discurso integracionista latinoamericano que ha construido un mundo propio. Este discurso ha construido un lenguaje con objetivo político pero que ha acabado más próximo de la literatura por el carácter épico que suele tener.

Efectivamente el discurso integracionista latinoamericano es, sin duda, atractivo y concita acuerdos, pero a la vez surge como irrealizable. ¿No es ello una aporía? Quizás en el más bello de los conceptos integracionistas habita dicha aporía: América Latina como la "Patria Grande". Es decir, en el integracionismo latinoamericano basado en un "nacionalismo continental". ¿No ha sido el nacionalismo el principal pensamiento (y sentimiento) de los estados latinoamericanos dentro de una geopolítica de fronteras? No podemos dudar de la sinceridad de los notables pensadores latinoamericanos al creer que nacionalismo e integración continental eran dos piezas de una misma totalidad. Como la Editorial Universitaria le publica una serie de ensayos bajo el título de "Nacionalismo 
Latinoamericano", Felipe Herrera lo interpreta como el interés de dicha empresa "por los valores de nuestra identidad regional". (Herrera, 1983:15). Fue el propio Felipe Herrera quien se percató que en el origen de la integración latinoamericana estuvo el factor que la hizo imposible, señala que Bolívar (y los otros próceres) "fracasa en sus intentos porque ya están en juego las fuerzas que han de producir -o han de contribuir en parte en ello- la dislocación latinoamericana". (1997:197). Es por ello que puso todo su empeño en la integración económica y secundariamente en la política. El idealismo de estos próceres ha prevalecido por sobre el realismo en lo que respecta a la integración continental, influyendo en la política internacional hasta 1989 , cuando los tratados de libre comercio comienzan a abrir un camino nuevo de integración.

¿Cuál ha sido la principal aporía del pensamiento integracionista? Es decir, ¿cuál ha sido el principal nudo que el razonamiento no ha podido desatar en el pensamiento integracionista?, ¿qué obstáculo lo ha puesto contra sus límites? En nuestra opinión ese ha sido el nacionalismo y la soberanía de los estados nacionales, elementos que han impregnado los vínculos internacionales que han sostenido las sociedades de la región por casi dos siglos; determinando el sentido de sus acciones y el entramado institucional que da forma a la integración latinoamericana a lo largo del siglo XX y los inicios del XXI. Se trata de la búsqueda de una identidad latinoamericana basada en la reivindicación de lo propio o lo autóctono, que destaca la independencia y la búsqueda de un destino autónomo (Devés, 2000:97), pero a través de diversas vías, en ocasiones contradictorias.

En efecto, Eduardo Devés-Valdés, nos dice que "no todos han pensado lo mismo por integración o destacado las mismas dimensiones, incluso "hubo quienes propiciaron una integración defensiva, como una especie de sindicato de países pobres para defenderse de los ricos, otros con la idea de un nacionalismo continental, propusieron crear la nación Iberoamericana..." (Devés, 2007:19). Así es como se explica que el derrotero de la integración latinoamericana se encuentra marcado por definiciones contradictorias. Incluso en el más idealista de los discursos integracionistas su contradicción interna, el realismo y nacionalismo, donde la Patria, que fue construida no en pocos casos por Padres Fundadores que propiciaban la integración latinoamericana, era levantada como bandera de lucha entre los países hermanos. Un ejemplo notable de esa contradicción está en el pensamiento de Manuel González Prada: quien dice en una conferencia dada el 21 de agosto de 1889, entre otras frases belicistas: "Las naciones viven vida muy larga y no se cansan de esperar la hora de justicia. Y la justicia no se consigue en la tierra con razonamientos y súplicas: viene en la punta de un hierro ensangrentado..." (González Prada s/a: 198) Al igual que González Prada en cada país encontramos integracionistas latinoamericanos que dejan de serlo respecto de los países vecinos, con los que irónicamente deberían tener el espíritu de hermandad más abierto.

Quizás esa aporía nacionalismo-integración, no resuelta, responda a la pregunta sobre 
el proyecto político latinoamericano iniciado pero nunca acabado, cuyo sucedáneo ha sido un continente imaginado.

Álvaro Bello, poniendo la mirada en la filigrana de la sociedad latinoamericana, nos dice que "el nacionalismo identificado con el estado se ha constituido en una fórmula de inclusión ciudadana que excluye, por ser totalizadora, otras formas de inclusión distintas no definidas en función del estado nacional" (2007:7). Se refiere a los pueblos indígenas y al necesario reconocimiento de la diversidad cultural, concepto que ha estado ausente en el discurso integracionista latinoamericano, que más bien se ha visto influido por la modernidad. ¿Cabe en esa fórmula de inclusión ciudadana del estado-nación, una que considere a la ciudadanía latinoamericana? O, más bien, el ciudadano latinoamericano habita un lugar imaginado como el de Alicia en el país de la maravillas. En el capítulo primero de este libro, Alicia al ver un libro sin dibujos ni diálogos se pregunta: “¿Y de qué sirve un libro sin diálogos y dibujos? Del mismo modo nos podemos preguntar cómo ella: ¿Y de qué sirve un discurso sin realidad?

La consolidación de los estados nacionales con sus distintos resultados, donde prevalecen sus intereses nacionales a través de la búsqueda del equilibrio subregional, de esferas de influencia; de la existencia de guerras fronterizas; etc., ${ }^{1}$ apunta hacia un proyecto de frontera que, como dijo Lepoldo Zea, avanza empujado sin integrar. (2000:9) Entonces, a pesar de los discursos, no ha sido posible para los integracionistas desnaturalizar esas estructuras de relaciones internacionales decimonónicas al interior de América Latina y pasar a nuevos tipos de acuerdos, sin desconocer lo que fueron en su momento el ALALC, Pacto Andino, ALADI, el MERCOSUR, etc., y lo que es actualmente UNASUR, empero respondieron a liderazgos y a áreas de influencias al interior del continente que, al parecer, aún persisten.

El concepto de integración ha pasado por diversas etapas, pero en ninguna de ellas ha podido desatar el nudo de la aporía. Raúl Bernal-Meza distingue las siguientes etapas en la integración latinoamericana: "La primera etapa correspondía a la época del movimiento de la independencia de los países latinoamericanos, en la cual la generación de los libertadores y personeros de la elite política e intelectual de esos tiempos desarrolló una conciencia integracionista, pero sin una estrategia adecuada para realizar la unidad latinoamericana. Existía la visión y la conciencia de América Latina como un todo, como una unidad geográfica, cultural e histórica, pensamiento que fue común en la visión de los Libertadores. La segunda etapa correspondió a la época de la formación y desarrollo de los nacionalismos latinoamericanos, que se extiende entre el periodo de desaparición de la

\footnotetext{
${ }^{1}$ Hay bastantes trabajos, actualmente, que desde la perspectiva de la historia de las relaciones internacionales, algunos, y desde la teoría de las relaciones internacionales, otros, interpretan la realidad latinoamericana desde el lente del realismo. Dentro de la primera perspectiva destaca: (Lacaste, 2005); (González Miranda, 2004). Desde la segunda, aunque no tan actual: (Atkins, 1991); (Witker, 2000); (Bernal-Meza,2005).
} 
generación de los Libertadores hasta la Primera Guerra Mundial. En este periodo se propaga la «desintegración» y «fragmentación», a medida que se van consolidando los nacionalismos. Estos ceden a una conciencia integracionista en la medida que perciben graves peligros externos. La tercera etapa fue la época de desarrollo de una conciencia integracionista a nivel político, con una estrategia de penetración partidaria. Hay en este periodo una fuerte incidencia del antiimperialismo, con un compromiso de determinados partidos políticos con la integración latinoamericana; una etapa que fue desde los anos 20 hasta fines de los 70. La cuarta etapa es la época en que la corriente integracionista latinoamericana logra expresarse en una conciencia y en una estrategia de tipo económico que al principio se concibe en términos limitados, para alcanzar luego caracteres globales. Es en este periodo donde el pensamiento Cepalino comienza a cuajar en los primeros modelos, el Mercado Común Centroamericano y la ALALC. La quinta etapa, que correspondió a los anos 60 y 70, se caracterizó por una conciencia y estrategia globales de la integración al nivel económico, político e intelectual y es como la síntesis y proyección de todas las anteriores. Esta etapa, de la cual surgirán la reformulación de ALALC y su transformación en ALADI y el Pacto Andino, es la que consigue dar sustento teóricoconceptual a una nueva dimensión, compleja y global, de la integración” (2005:48).

Han existido distintas generaciones de integracionistas desde Bolívar y Martí a la fecha, Juan Montalvo, Francisco Bilbao, José Enrique Rodó, Manuel Ugarte, Domingo F. Sarmiento, Simón Rodríguez, Gabriel René Moreno, Pedro Henríquez Ureña, Eugenio María de Hostos, José Ingenieros, Mariano Picón Salas, Alfonso Reyes, Darcy Ribeiro, José Vasconcelos, Víctor Raúl Haya de la Torre, José Carlos Mariátegui, Gabriela Mistral, Raúl Prebisch, Felipe Herrera, Leopoldo Zea, Antonio García, Aníbal Pinto Santa Cruz, Fernando Enrique Cardoso, Osvaldo Sunkel, Octavio Ianni, Tomás Vasconi, etc. No solamente son de distintas generaciones sino de diversas ideologías y disciplinas. De tal modo el discurso integracionista se hecho más complejo.

No obstante, Alberto Moreiras denominaría al pensamiento de estos autores como un "latinoamericanismo de primer orden". Éste siente que el latinoamericanismo de "primer orden" estaría construido sobre conceptos de identidad y diferencias "anticuados", entonces llama a una deconstrucción de este discurso, en otras palabras a una nueva lectura desde este presente creando un discurso "latinoamericanista de segundo orden", es decir, aquel discurso latinoamericanista que versa sobre el latinoamericanismo como tal. Señala este autor: "He intentado ir a los momentos aporéticos del conocimiento latinoamericanista y empujar al latinoamericanismo contra sus límites" (Moreiras, 2001:299).

Beverley señala que "Moreiras sitúa su proyecto en la doble conjetura formada por la crisis del nacionalismo latinoamericano (y algunos de los paradigmas teóricos asociados a él, como la teoría de la dependencia o el de transculturación) y los efectos de la globalización y de la hegemonía neoliberal en la región". (2005:68) Este proyecto desvela 
una nueva problemática latinoamericana y la emergencia de un nuevo pensamiento latinoamericano. Beverley incluso compara el proyecto de Moreiras al de Homi Bhabha, pero no es el único que está pensando la región.

Han surgido nuevas corrientes de pensamiento continental que ameritan tomar un lugar en la discusión propia del pensamiento latinoamericanista. Entre ellos se encuentran el pensamiento crítico latinoamericano, que se ha inspirado en autores como José Carlos Mariátegui pero con la influencia europea de la escuela de Frankfurt, especialmente de Max Horkheimer, unido además al problema de la interculturalidad, donde autores como Catherine Walsh, Catalina León, entre otros, se destacan (Walsh 2005). En un plano filosófico encontramos el aporte cada vez más significativo de Martín Hopenhayn (1995). Filósofos, como Derrida, están influyendo notoriamente en este nuevo pensamiento deconstructivista latinoamericano, como aquel propuesto por Moreiras en "Fragmentos globales" (1998), las teorías sin disciplinas de Gómez-Castro y Eduardo Mendieta (1998), etc. Todos estos autores tienen un eje común: el post-colonialismo o el (de) colonialismo latinoamericanos.

Posiblemente quien ha reflexionado de modo más profundo la crítica al postcolonialismo o al (de)colonialismo sea Walter Mignolo, quien se hace la pregunta si existe una filosofía latinoamericana, no como un espejo de la europea sino propiamente latinoamericana, respondiéndose que "América Latina es una consecuencia y producto de una geopolítica del conocimiento, esto es, de un conocimiento geopolítico creado e impuesto por la modernidad, en su autodefinición como modernidad. En este sentido, "América Latina" se fue fabricando como algo desplazado de la modernidad, un desplazamiento que asumieron los intelectuales y estadistas latinoamericanos y se esforzaron por ser "modernos" como si la modernidad fuera un punto de llegada y no la justificación de la colonialidad" (2003:2). Este autor rechaza incluso la influencia de teóricos del primer mundo de las disciplinas propias de las ciencias humanas que más han aportado al estudio y reflexión del problema latinoamericano, a pesar de la influencia de ciertos pensadores europeos precisamente en la discusión sobre el latinoamericanismo postcolonial, como Gramsci (Strozzi, 2002) o Habermas (Castro-Gómez, 1998).

Los estudios culturales han sido también una fuente relevante, especialmente los estudios de García Canclini (1989), entre otros, para una nueva discusión sobre la cultura latinoamericana, como la realizada por Nelly Richard (1998). La problemática de la interculturalidad, si bien se inicia tempranamente con la revolución mexicana hacia 1910 y tuvo un auge relevante en Bolivia con Warisata, además de otras experiencias educativas importantes como en Puno, Perú, o en Ecuador, todavía requiere de un desarrollo mayor, donde aportes teóricos como los de Tzvetan Todorov (2004) u Homi Bhabha (1983) se destaquen, entre otros notables autores no latinoamericanos que ya se encuentran en los curricula universitarios. Aunque algunos autores latinoamericanos ameritan un mejor lugar en la discusión académica, como el caso de Rodolfo Kusch. 
Posiblemente uno de los ríos más correntosos en el nuevo pensamiento latinoamericano sean los estudios de fronteras. Esos estudios se han fortalecido frente a la importancia que adquieren algunos fenómenos, como los migratorios. La problemática de la migración ha comenzado a transformarse en clave para entender las dinámicas y la estructura de la sociedad latinoamericana. En México, dos importantes Colegios, el de la Frontera Norte y el de la Frontera Sur, están produciendo estudios sobre la movilidad internacional transfronteriza. Entre el gran material producido por estas instituciones podemos destacar la revista Estudios Fronterizos, donde se han editado resultados de investigaciones como la de Marcos Cuevas Peras (2005), en quien observamos un esfuerzo por comparar las nociones y representaciones de frontera entre Estados Unidos y América Latina. Sin embargo, también la reflexión teórica, basada en la filosofía no está ausente, como es el caso de José Luis Tejeda (2004), quien desde Heidegger y Nietzsche, analiza la "línea" y la frontera. Más aún, Esebio Medina García (2006) propone una epistemología para los estudios de fronteras internacionales. Nicole Deisbach de Rocherfort (2002), plantea incluso un nuevo paradigma en la comprensión de la realidad, donde el concepto de frontera, interna y externa, es el eje de la discusión. Existen otras instituciones que comienzan a analizar de modo sistemático en América Latina, especialmente en México, el problema fronterizo, como ejemplo podemos citar el trabajo de María Zavala de Cosio sobre la frontera norte y su aspectos demográficos (1997).

El Convenio Andrés Bello ha impulsado la reflexión y análisis de espacios fronterizos específicos entre los países latinoamericanos, editando una Serie de Cuadernos llamada Integración Social y Fronteras, donde se han publicado investigaciones sobre las triplefronteras paraguaya, argentina y boliviana (Stahringer 2007), ecuatoriana, colombiana y peruana (Walsh y Santacruz 2006) y peruana, boliviana y chilena (González, 2006b y 2007), las zonas de integración fronteriza de la comunidad andina (Ramírez, 2006), etc.

Un libro particularmente llamativo, Teoría de la Frontera: Los Límites de la Política Cultural, es de los autores-editores Scout Michaelsen y David E. Jonson, y ofrece una discusión académica en torno al problema de las fronteras, siendo el aporte de Alejandro Grimson el más novedoso. Este libro es también una revisión bibliográfica del aporte de diversas disciplinas sobre el tema fronterizo, aunque predomina el problema norteamericano y mexicano. Por cierto, existen otros debates que enriquecen el problema señalado, como aquel entre Hevilla (1998) y Escamilla (1999), donde se aborda el problema de la organización del territorio y la emergencia de la frontera como fenómeno de conflicto. Cristina Hevilla realiza un estado del arte sobre las nuevas miradas a la problemática de la frontera, sosteniendo que los espacios fronterizos han dejado de ser los espacios marginales o alejados, para transformarse en centrales.

La mirada de la frontera como espacio liminal es el eje de la propuesta de Alejandro Grimson. El fenómeno liminal que se ha expresado en América Latina hasta fines del siglo 
veinte ha sido el mismo: el límite hasta donde podían llegar las fronteras, pero más que fronteras reales o territoriales, se trataba de fronteras políticas o mentales. Desde esta perspectiva, como señala Alejandro Grimson, es "necesario distinguir con claridad dos tipos de frontera que se confunden en el debate actual: las fronteras culturales de las identitarias; las fronteras de significados de las fronteras de sentimientos de pertenencia. Esto es clave y (...) podría sintetizarse en la afirmación, por cierto esquemática, de que las culturas son más híbridas que las identificaciones. (Grimson, 2004:3) Por cierto, nuestra propuesta desafía lo afirmado en la medida que busca generar nuevas identidades en torno a la integración regional que posibiliten, además, abordar la limitación de estas fronteras mentales. En definitiva, se trata de llegar más allá de esos límites.

En el campo de las relaciones internacionales ya se habla de fronteras perforadas (Soldatos, 1996), para denotar que ellas están cada día más permeables a las migraciones y la movilidad, al comercio y la cooperación, a la tecnología y la información, en definitiva a la paradiplomacia, pues "remiten parte importante de la perforación de la soberanía a los actores subnacionales, que emanan de las regiones, de las ciudades (...) en su esfuerzo por internacionalizarse y encontrar un lugar activo en el proceso globalizador" (Witker, 2004:82).

¿Por qué, para solucionar el dilema entre integración y frontera, debemos eliminar uno de estos conceptos? Eso hacemos cuando hablamos de ciudadanos sin fronteras, entre tantos conceptos que tienen esa referencia. Sin embargo, para los sujetos que han vivido en la frontera, sean éstas políticas o culturales, saben que ellas expresan una realidad que no sólo tiene sentido sino también sentimiento.

Incluso pensadores latinoamericanistas, como Alberto Saladino García, han intentado re-definir el concepto de frontera, cambiando su epistemología nacida de la geopolítica decimonónica por otra más integradora, haciéndola sinónimo con la identidad latinoamericana, por lo mismo, ven a la frontera como "un concepto positivo que en su empleo sintetiza las ideas de conexión, vínculo e interdependencia de nuestras sociedades". (Saladito García, 2002:15) Eusebio Medina García agrega "poner énfasis en lo transfronterizo, delimitando espacios de interacción e intercambios que comprendan ambos lados de una misma frontera" (Medina, 2006:20)

Alberto Saladino García, nos dice que autores como Antenor Orrego, Darcy Ribeiro, Pablo González Casanova, son "latinoamericanistas (que) emplean el concepto de frontera como nexo más que como separación, particularmente con la intención de mostrar las coincidencias que les permitan orientar sus esfuerzos para la superación de su situación de dominación". Donde, por cierto, el concepto de frontera cultural es el que predomina.

El concepto de frontera tiene gran fuerza porque hace referencia al territorio, al habitar, a la vida cotidiana; es telúrica. Como muy bien nos recuerda Sergio Boisier, hay 
quienes equivocadamente han proclamado la muerte del territorio producto de la globalización, pues "el territorio juega un papel más importante que en el pasado. No hay que confundir el territorio con la distancia, ni la geografía con el mapa". (Boisier: 8) Del mismo modo, no podemos confundir la Frontera-territorio con la Línea de Frontera. En la primera caminan personas, la segunda es objeto de la diplomacia. Por su parte, no podemos confundir integración con asimilación, la primera apela a la aceptación de otro y la segunda a transformarse en el otro.

En suma, el objeto llamado integración se inserta en una historia latinoamericana que le da sentido. La primera tarea que posibilita su estudio crítico consiste en deconstruir su noción, pues la deconstrucción "se presenta como un momento de desmitificación, en la medida en que socava las evidencias en que estos objetos se fundan .La deconstrucción, aquel particular momento analítico que intenta sacar a la luz los aspectos, las lógicas, dinámicas y propiedades de los objetos sociales que, de otro modo, tenderían a permanecer implícitos" (Joignant, 1999:33)

Quizás, para superar el cientificismo que opera en las Relaciones Internacionales, que impide ir más allá de la racionalidad que impera, "es legítimo preguntarse si sus objetos empíricos no suponen condiciones culturales que le aportan centralidad a las acciones individuales." (Joignant, 1999:33). No considerando la capacidad de las ideas e instituciones que le dan sentido a estas acciones individuales, que promueven procesos de cambio pacífico ajustadas a las nuevas dinámicas internacionales; con el decidido propósito de ampliar las escalas de actuación de la integración regional, generando acciones en este campo, que den cause a estos nuevos espacios, como es la emergencia de lo transfronterizo.

\section{Dilemas de la integración: desatando el nudo}

Como plantea Phillip Schmitter, refiriéndose a los procesos de reintegración latinoamericana surgidos al alero de la democratización del continente a finales de la década de los 80', mientras sea mayor la participación de la comunidad interesada en intervenir en actividades propias de la integración, actuando libremente con el apoyo de la autoridad , mayor será la posibilidad de reciprocidad entre los interesados y más fácil será la búsqueda de acuerdo entre las partes, logrando mejores condiciones para una respuesta asociativa. Sin embargo, señala que, además de aflorar los intereses, también surgen pasiones basadas territorialmente, ya sean planteamientos nacionalistas o étnicos, los cuales obedecen a dinámicas conflictivas internas ya sean históricas o más coyunturales, pero -y esto es lo importante- que los procesos de integración pueden activar.

De lo expuesto se desprende, en palabras de Schmitter, "que el proceso se ve bastante diferente si se enfoca sólo desde la perspectiva de los intereses basados funcionalmente, concebidos racionalmente, que buscan el sitio y nivel que parece garanticen la más alta 
satisfacción al menor costo posible, que si se enfoca desde las pasiones territorialmente y simbólicamente concebidas que buscan la más alta seguridad al mayor nivel posible de soberanía"(Schmitter,1989:120) En síntesis, "en democracia la integración puede convocar a una diversidad de actores y proveer una mesa de negociaciones en la cual éstos pueden exponer sus intereses y aspiraciones funcional y racionalmente constituidos, y además pueden exponer y hasta transferir sus aprehensiones colectivamente elaboradas a las nuevas reglas del juego" (Ibid). Reglas que se concretan en los acuerdos suscritos en toda iniciativa de integración.

No debe olvidarse que todo ejercicio político, como la integración, genera rivalidad entre proyectos, "por tanto no puede escapar de la subjetivación, o sea del hecho que hay actores que definen la realidad filtrada por los marcos de aprehensión de ella y que, por tanto -por más racional que sea- sus acciones están expuestas a errores de diagnóstico, de información y de cálculo (Moulian 2000:17).

En tanto, Paul Ricoeur señala que "toda acción social está mediada simbólicamente y que es precisamente la ideología lo que desempeña este papel de mediación en la esfera social; siendo más precisos, ella preserva la identidad social y de ahí su carácter integrador. Sólo sobre la base de esta función integradora de la ideología pueden cobrar sentido pleno los otros significados de ella, como deformación y legitimación (Longás 2002:16). Por tanto, si queremos apuntar a un nuevo concepto de integración, no podemos disociar intereses racionales y aprehensiones colectivamente elaboradas sino, más bien, indagar en cómo se vinculan y dan sentido a la integración, ${ }^{2}$ y en cómo han devenido en deformación. Desde esta premisa, entonces, podríamos plantear una integración que supere la aporía integración/nacionalismo. Pues, el nacionalismo o amor a la nación como una inclinación natural, una fuerza vital (Osorio, 2001) muchas veces es promovida por las dirigencias políticas en crisis. Como plantea Longás: "sólo cuando el sistema de autoridad existente entra en crisis y pretende perpetuarse por medio de la imposición fáctica, la ideología abandona su función legitimadora y pasa a funcionar como deformadora toda vez que pretende salvar la distancia entre autoridad y dominación abogando por la continuidad del sistema imperante.(Ibid) Finalmente señala: "Ricoeur monta su teoría sobre la ideología

\footnotetext{
${ }^{2}$ En efecto, Ricoeur plantea que "los hombres pueden vivir sus conflictos sociales gracias a que sus propias acciones aparecen tejidas por un sistema simbólico que les ayuda a interpretar dichos conflictos. Para Ricoeur, el proceso de interpretación es tan primitivo que en realidad constituye la dimensión misma de la praxis. Así nos encontrarnos con el significado positivo de la ideología que es preciso considerar al reformular su oposición originaria con la praxis. Para los seres humanos no es posible un modo de existencia no simbólico y, menos aún, un tipo no simbólico de acción. A esta dimensión simbólica de la praxis Ricoeur denomina ideología resaltando así un aspecto de ella, precisamente el que él llama constructivo, hasta ahora no considerado por sus teóricos. A partir de esta tesis central, Ricoeur se aboca (...) a desarrollar su teoría sobre la ideología como legitimación y la ideología como integración. Estos significados de la ideología vienen a perfeccionar y completar el concepto".(Longás, Ibid)
} 
como legitimación en la cual es particularmente significativo el valor que le confiere a las instituciones..." ( Ibid) Tema que en el campo internacional ha tomado relevancia desde renovadas aproximaciones teóricas. Lo trataremos a continuación.

\section{Superación del dilema de la integración}

Para la generación de nuevos tejidos sociales en torno a la integración regional, de los que se desprenda este discurso de segundo orden, tenemos que considerar la nueva realidad en que progresivamente, desde hace ya dos décadas, se ha venido forjando este proceso de cambio.

Este nuevo proyecto político modernizador ha cabalgado por todo el territorio latinoamericano desde los años ochenta del pasado siglo: de la mano de la democratización del continente, el neoliberalismo y la globalización, como un fenómeno cultural ineludible, han sido los elementos determinantes de un nuevo continente. Para Zaki Laïdi, la respuesta obligada a la arremetida de estos fenómenos será -y de hecho ya lo es hace una década- a distintas velocidades, la emergencia de conglomerados de integración supranacional, imponiéndose como la referencia principal del sistema mundial, producto de la pérdida de centralidad del Estado-nación como protagonista de la mundialización. ${ }^{3}$ Para Laïdi, a propósito de la mundialización y la crisis de sentido que acarrea: "ningún actor político, social o económico se ofrece como voluntario para proponernos una interpretación, para presentar un proyecto capaz de ayudarnos a vivirla con serenidad, para permitirnos integrarla a un proyecto colectivo, para asignarle cierta positividad. Ante ella el Estado se encuentra desamparado: se encuentra incapaz de decirnos si constituye un bien, un mal, un peligro o un triunfo, cuando la demanda de sentido es muy fuerte (Laïdi, 1997:32) Continúa Laïdi: "Según las regiones, y en proporciones muy variables", este gran movimiento reflejará y ampliará tres dinámicas: la descentralización del poder, la voluntad de los estados de encontrar un nuevo espacio de regulación y legitimación de su acción ante el encogimiento nacional, y las demandas de sentido confusas y contradictorias que emanan de de las sociedades interesadas en conjugar la mundialización con la proximidad." (Ibid). Así vistas las cosas, el énfasis en esta propuesta teórica está dado en la percepción que tenemos nosotros mismos del fenómeno internacional en el que aparece la integración como la respuesta deseada.

Como se desprende de Laïdi, a consecuencia de este proceso de regionalización, también en este nuevo período están emergiendo con un poder inesperado los gobiernos locales o municipales, que comienzan a presionar por una mayor descentralización en todos

\footnotetext{
${ }^{3}$ Para Zaki Laïdi, "el gran desafío de la mundialización deriva de nuestra dificultad de objetivarla, de representárnosla y de invertir personalmente en ella, afectiva o colectivamente, por razones distintas a la necesidad económica" (Laidi 1997:32)
} 
los países, donde las comunidades perciben un poder hasta entonces desconocido. ${ }^{4}$

En síntesis, tres fuerzas han irrumpido en el nuevo escenario, ansiosas por recobrar sentido, ${ }^{5}$ una desde lo internacional, la globalización y su respuesta la regionalización, otra desde lo nacional, la descentralización, y la tercera desde lo local, la municipalización; todas coincidiendo en un espacio banal y en un espacio real; es decir, en una nueva manera de entender el territorio. En ese escenario las fronteras comienzan a transformase en obstáculos para el nuevo desarrollo y los estados-nacionales a perder el control de las mismas. Las plataformas de servicios, las alianzas estratégicas entre ciudades, las redes internacionales, las compañías transnacionales, etc., pero por sobre todo la paradiplomacia, han replanteado el problema de la integración latinoamericana.

Nuevos ciudadanos recorren las fronteras vestidos de empresarios, estudiantes, agentes culturales, académicos, turistas, emigrantes en busca de empleos, etc. Los gobiernos locales comienzan a tener un papel cada día más esencial como, por un lado, contenedores de estos nuevos flujos $\mathrm{y}$, por otro, como agentes con capacidad de negociación a escala global, donde organismos internacionales, públicos y privados, les entregan la llave de la cooperación descentralizada. La glocalización, entonces, es un fenómeno que se puede observar en América Latina hasta en lugares considerados marginales y perdedores hasta hace un par de décadas atrás, especialmente regiones fronterizas que permanecían atrasadas como consecuencia de hipótesis de conflicto.

Entonces -como dijimos-, las interrogantes necesarias de abordar serían: ¿es posible desnaturalizar esas estructuras internacionales reificadas ${ }^{6}$ y pasar a nuevos tipos de relaciones que asuman la existencia de nuevas formas y visiones que las legitimen? ¿Podrá

\footnotetext{
${ }^{4}$ Para profundizar en la experiencia chilena de este fenómeno, específicamente en los proyectos de integración transfronteriza a escala local, presentes en la triple frontera norte (Región de Tarapacá y Arica Parinacota con sus vecinos peruanos y bolivianos) y sus alcances, ver: (Rouviére, 2007), (Bello, 2007), (González, 2006), (González, Rouviere, Ovando).

${ }^{5}$ Considerando que lo regional engloba alas dos restantes. "Es probable que a escala regional surjan nuevos itinerarios colectivos de sentido capaces de tomar en cuenta las tres demandas del sistema social mundial: la demanda de seguridad, la necesidad de identidad y la búsqueda de legitimidad." (LaidiOp. Cit. p.191

${ }^{6}$ Wendt lo plantea de la siguiente forma: "He tratado de esbozar en qué debería consistir esta agenda de investigación (...). Su objetivo debería ser valorar la relación causal entre la práctica y la interacción (como una variable independiente) y las estructuras cognitivas en el nivel de estados individuales y de los sistemas de estados que constituyen identidades e intereses (como variable dependiente) _es decir, la relación entre lo que los estados hacen y lo que son. Puede que tengamos alguna noción a priori sobre la idea de que los actores estatales y las estructuras sistémicas son "mutuamente constitutivas", pero esto nos dice poco si no tenemos conocimiento de cómo se forman los mecanismos de la interacción diádica, triádica y entre n-actores y cómo a su vez son formadas por las "reservas de conocimiento" que colectivamente constituyen las identidades y los intereses y, más ampliamente, conforman las estructuras de la vida internacional. En este sentido, es particularmente importante el papel de la práctica en dar forma a actitudes que conciban las estructuras como algo dado. ¿Cómo y por qué los actores reifican las estructuras sociales, y bajo qué condiciones desnaturalizan estas reificaciones?" (Wendt, Alexander, 2005).
} 
el razonamiento desatar los diversos nudos que la sociedad (especialmente a partir de 1989) le ha impuesto al pensamiento integracionista?

Edgar Vieira responde de la siguiente manera: "Construir supone la posibilidad de modificar la manera mediante la cual se ha hecho la integración, desde lo alto de ciertas elites hacia abajo sin participación significativa de la sociedad, lo que podría ser especialmente interesante para la reformulación de la orientación y de los principios de los procesos de integración en América Latina, para construir la integración no solamente por los Estados-nación, sino también por otras fuerzas sociales, como las regiones." (Vieira, 2005,275) Actores subnacionales que luchan por su reconocimiento como actores válidos de la nueva escena internacional marcada por la glocalización y su variante las regiones transfronterizas.

Así visto el nuevo panorama latinoamericano, la forma de abordar una nueva categoría de integración pasaría por redefinir el espacio de la integración latinoamericana que pensamos y anhelamos. Teniendo en cuenta que "los lugares, espacios y escalas no son predeterminados, sino que son sujetos a luchas discursivas sobre mapeo y denominación" (Jessop, 2004: 27). Nos faltaría elucidar cómo esas nuevas definiciones lograrían plasmarse en la realidad internacional, pues las luchas más sustantivas sobre estas nuevas ideas se encuentran en su "institucionalización social, material y espacio-temporal" (Ibid).

Las nuevas respuestas que aporta el renovado debate dentro de las Relaciones Internacionales, "se asocian a cuestionamientos sobre la supuesta neutralidad valorativa y objetiva de las teorías tradicionales, [estas nuevas aproximaciones] defienden el vínculo entre conocimiento, historia, cultura y relaciones de poder y prestan más atención al lenguaje, a la construcción lingüística y al discurso".( Vieira, 2005:272) En este cambio, una de las aproximaciones, el constructivismo, se centra en redefinir nuevos intereses e identidades e institucionalizar nuevas relaciones sociales en el campo de las relaciones internacionales y particularmente en el de los procesos de integración.

Imbuidas en este proceso de cambio de paradigma dentro del debate actual de las Relaciones Internacionales, algunas de sus principales preocupaciones se han centrado en los siguientes aspectos: primero, el tender a privilegiar como objeto de estudio el proceso de cambio pacífico en las relaciones internacionales y su dinámica cooperativa, por sobre la estructura existente; segundo, prevalecer el análisis en la cultura y las identidades de los actores, no sólo en las conductas y decisiones racionales de éstos. Ambos aspectos 
relacionados y esenciales para entender los aspectos intersubjetivos de las relaciones internacionales (Salomón, 2002; Murillo, 2004; Wendt, 2005).

Desde esta perspectiva de nuevas escalas imaginadas, frontera e integración son indisolubles. Frontera es un concepto liminal pero a la vez es un concepto de apertura. Toda frontera indica término y comienzo. En cambio el concepto de integración es más abstracto, pues apela a elementos ideológicos, la fuerza de este concepto se sustenta en una conciencia activa a la que ha optado. Unirlos es sintetizar teoría y praxis: la "frontegración". El campesino que vive en la frontera y tiene papeles de identidad de ambos países, cruza la raya internacional como quien camina por el paso de cebra de una calle, cambia la cinta del sombrero según el país donde se encuentre, es un "frontegrizo". Mutatis mutandis, el intelectual que reconociendo las fronteras y sus definiciones, aboga por la integración, la cooperación descentralizada y la paradiplomacia entre los países del continente, son "frontegrizos".

Para finalizar, nos preguntamos si podrá emerger una corriente de pensamiento que, venida desde los propios estados-nacionales, organismos supranacionales o de las sociedades civiles, pueda construir una comunidad epistémica promotora de esta nueva integración latinoamericana. 


\section{Bibliografía}

Aguirre, Beltrán Gonzalo (1973), Regiones de refugio, INI SEP, México.

Atkins, Pope (1991), América Latina en el Sistema Político Internacional, Grupo editorial latinoamericano, Buenos Aires.

Bello, Álvaro (2004), Etnicidad y ciudadanía en América Latina, la acción colectiva de los pueblos indígenas, CEPAL-GTZ, Libros de CEPAL No. 79, Santiago.

Bernal-Meza, Raúl (2005), América Latina en el mundo. El pensamiento latinoamericano y la teoría de las relaciones internacionales, Nuevohacer, Grupo editorial latinoamericano, Buenos Aires.

Beverley, John (2005), "Deconstrucción y latinoamericanismo. Notas sobre The Exhaustion of Difference de Alberto Moreiras" en La deconstrucción y el retorno de lo político, Universidad ARCIS, Santiago.

Bhabha, H. K (1983), "Difference, Discrimination and the Discourse of Colonialism", en Barker, Francis (ed.), The Politics of Theory, Essex University Press, Colchester.

Idem (1984), "Representation and the Colonial Text: Some Forms of Mimeticis", en Frank Gloversmith (ed.) The Theory of Reading, Harvester, Brighton.

Idem ( 1986), "Signs Taken for Wonders: Questions of Ambivalence and Authority under a Tree Outside" en Gates, Louis Henry Jr. (ed.), "Race”,Writing and Difference, Chicago, The University of Chicago Press, Chicago.

Boisier, Sergio (2003), " $¿ Y$ si el desarrollo fuera una emergencia sistémica? en Revista del CLAD, Reforma y Democracia, № 27, octubre de 2003, Caracas.

Boisier, Sergio (2005), "Globalización, integración supranacional y procesos territoriales locales: ¿hay una sincronía? en Revista de la CEPAL $\mathrm{N}^{\circ} 86$, agosto de 2005, Santiago.

Calderón, Fernando; Martín Hopenhayn, y Ernesto Ottone (1994) "Una perspectiva cultural de las propuestas de la CEPAL" en Revista de la CEPAL $\mathrm{N}^{\circ}$ 52, abril de 1994, Santiago.

Castro-Gómez, Santiago y Medienta, Eduardo (Editores) (1998), Teorías sin disciplinas: latinoamericanismo, poscolonialidad y globalización en debate. Universidad de San Francisco, México. 
Cuevas Peras, Marco (2005), "Fronteras y representaciones fronterizas: aproximaciones comparativas entre Estados Unidos y América Latina”. Estudios Fronterizos, vol 6, № 11, enero-junio, México.

Deisbach de Rochefort, Nicole (2002), "Frontera: ¿muro divisorio o tejido de relaciones?" en Estudios Fronterizos, vol 3, N 5, México.

Devés, Eduardo (2000), Del Ariel de Rodó a la CEPAL (1900-1950), Editorial Biblos, Buenos Aires.

Idem (2002), "Espacio intelectual, integración latinoamericana y sociedad civil: la planética y la ubicación de un nicho en el medio ambiente global", en Estudios Trasandinos. $N^{o} 7$. Universidad de Santiago de Chile, Segundo semestre, Santiago.

Idem (2007), Cartas a la intelectualidad, estudiantes universitarios y profesionales del conocimiento de América Latina y el Caribe, Editorial Grafitti, Santiago.

Escamilla, Francisco (1986), "En torno a la problemática neohistórica. Un enfoque crítico" en Boletín de la Academia Nacional de la Historia, Tomo LXIX, No 273, enero-marzo, Caracas.

Idem(1999), "El significado del término Frontera" en Revista Bibliográfica de Geografía y Ciencias Sociales, N 140, Universidad de Barcelona, Barcelona.

García Canclini, Nestor (1989), Culturas híbridas. Estrategias para salir o entrar a la modernidad. Ed. Grijalbo, México.

González Miranda, Sergio (2004), «Pax castrense en la frontera norte: Una reflexión en torno a la post-guerra del Salitre: el conflicto por Tacna-Arica y Tarapacá» en Universum. [online]. 2004, vol.19, no.1 [citado 29 Octubre 2008], p.28-57. Disponible en: <http://www.scielo.cl/scielo.php?script=sci_arttext\&pid=S0718237620040001000 03\&lng=es\&nrm=iso>. ISSN 0718-2376

Idem (2006), Arica y La Triple Frontera. Integración y Conflicto entre Bolivia, Perú y Chile, Editorial Aríbalo, Santiago.

Idem (2006b), Densidad, integración y conflicto en la triple frontera (Perú, Bolivia, Chile), Serie Integración Social y Fronteras, CAB, Bogotá.

Idem (2007), La emergencia de la triple frontera andina (Perú, Bolivia, Chile). Serie Integración Social y Fronteras No 3, CAB, Bogotá.

González Prada, Manuel, Horas de lucha, Ed. Pluma de Oro, Lima, sin año. 
Grimson. Alejandro (2004), Fronteras, naciones y región, Fórum Social das Américas, Quito, Equador, 25 a 30 de julho de 2004, Um projeto IBASE, em parceria com ActionAid Brasil, ATTAC Brasil e FundaçãoRosa Luxemburgo.

Herrera Lane, Felipe (1982), América Latina: viejas y nuevas fronteras., ECIEL, Río de Janeiro.

Idem (1983), Comunidad Latinoamericana de Naciones. Presencia de Chile, Editorial Universitaria, Santiago.

Hevilla, María Cristina (1998), «El estudio de la frontera. Una aproximación bibliográfica» en Revista Bibliográfica de Geografía y Ciencias Sociales, № 125. Universidad de Barcelona, Barcelona.

Hopenhayn, Martín (2002), «Ciudadanía descentrada en tiempos de globalización» en Marco Antonio Calderón; Willem Assies y Ton Salman (comps.), Ciudadanía, cultura política y reforma del Estado en América Latina, El Colegio de Michoacán, IFE Estatal, Zamora.

Idem (2001), "Viejas y nuevas formas de la ciudadanía" en Revista de la CEPAL No. 73, abril de 2001, Santiago.

Idem (1995), Ni apocalípticos ni integrados. Aventuras de la modernidad en América Latina, Fondo de Cultura Económica, México.

Jessop Bob. "La economía política de la escala y la construcción de las regiones transfronterizas" en Revista Eure (Vol. XXIX, N 89), mayo 2004, Santiago de Chile.

Joignant, Alfredo y Menéndez-Carrión, Amparo (1999), "De la democracia de los acuerdos a los dilemas de la polis: ¿transición incompleta o ciudadanía pendiente?", en Joignant Alfredo y Menéndez-Carrión, Amparo (eds.) La caja de Pandora: el retorno de la transición chilena, Planeta, Santiago.

Lacoste, Pablo. 2005. “Argentina y Chile (1810 - 2000), en: Pablo Lacoste, (comp.) Argentina, Chile y sus vecinos. Tomo II. Colección Cono Sur. Mendoza, Editora Andina Sur Caviar Blue, Instituto de Estudios Internacionales INTE, Universidad Arturo Prat. Iquique

Laidi, Zaki (1997), Un mundo sin sentido, Fondo de Cultura Económica, México.

Longás, Fernando (2002), "El Falso Dilema de la Teoría de las Dos Libertades: Reflexiones en Torno a una Ampliación del Concepto de Ideología" en Persona y Sociedad Vol. XVI, No 2, agosto de 2002, Santiago de Chile. 
López, Luís Enrique (2007), «Diversidad cultural, multilingüismo y reinvención de la educación intercultural bilingüe en América Latina» en Universitas. Revista de la Universidad Politécnica Salesiana de Ecuador, Año V. N ${ }^{\circ}$.

Mariátegui, José Carlos (1996); (1928), Siete ensayos de interpretación de la realidad peruana, Editora Amauta, Lima.

Medina García, Eusebio (2006), “Aportaciones para una epistemología de los estudios sobre fronteras internacionales" en Estudios Fronterizos, vol. 17, $\mathrm{N}^{\circ} 13$, enero-junio.

Mignolo, Walter (1998), "Posoccidentalismo: el argumento desde América Latina" en Castro-Gómez, Santiago y Medienta, Eduardo (eds.), Teorías sin disciplinas: latinoamericanismo, poscolonialidad y globalización en debate, Universidad de San Francisco, México.

Moulian, Tomás (2000), Socialismo del siglo XXI. La quinta vía, LOM, Santiago.

Moreiras, Alberto (1998), "Fragmentos globales: latinoamericanismo de segundo orden" en Castro-Gómez, Santiago y Medienta, Eduardo (eds.), Teorías sin disciplinas: latinoamericanismo, poscolonialidad y globalización en debate, Universidad de San Francisco, México.

Moreiras, Alberto (2001), The exhaustion of difference. The politics of Latin American, Cultural Studies, Duke University Press, Durham.

Murillo, Zamora, Carlos (2004), “Aproximación a los regímenes de integración Regional" en Revista Electrónica de Estudios Internacionales, $\mathrm{N}^{\circ}$ 8/, AEPDIRI, España. Disponible en http://www.reei.org.

Osorio Gonnet, Cecilia (2001), «Chilenos, peruanos y bolivianos en la pampa: 18601880. ¿un conflicto entre nacionalidades?» en Historia (Santiago). [online]. 2001, vol.34 [citado 29 Octubre 2008], p.117-166. Disponible en: $<$ http://www.scielo.cl/scielo.php?script=sci_arttext\&pid=S0717$71942001003400005 \& \operatorname{lng}=e s \& n r m=i s o>$. ISSN 0717-7194.

Pagano Fernández, Carlos (1999), Un modelo de filosofía intercultural: Rodolfo Kusch (1922-1979). Aproximación a la obra del pensador Argentino, Concordia, Aachen.

Polanyi, Karl (1957), The Great Transformation: The Political and Economic Origins of Our Time. Beacon Press by arrangement with Rinehart \& Company, Inc., Boston. 
Ramírez, Socorro (2006b), Las zonas de integración fronteriza: desafíos de la Comunidad Andina y Suramericana, Serie Integración Social y Fronteras, CAB, Bogotá.

Idem (2006), Ámbitos diferenciados de las fronteras colombianas, Serie Integración Social y Fronteras No 2, CAB, Bogotá.

Richard, Nelly (1998), Residuos y metáforas, ensayos de crítica cultural sobre el Chile de la transición., Ed. Cuarto Propio, Santiago.

Rouvière Laetitia (2007), «¿Un territorio político transfronterizo? Formas de legitimación de acción política intermunicipal entre Bolivia, Chile y Perú (BCP): el caso de la Alianza Estratégica Aymaras Sin Fonteras» en Revista Electrónica Parinas, volumen III, $\mathrm{N}^{\circ}$ 1, Universidad Arturo Prat.

Saladito García, Alberto (2002), "Epistemología del concepto frontera en el pensamiento latinoamericano" en Zea, L. y Taboada H. (comp.) Frontera y globalización, FCE, México.

Salomón, Mónica (2002), "La Teoría de las Relaciones Internacionales en Los Albores del Siglo XXI: Diálogo, Disidencia, Aproximaciones." en Revista Electrónica de Estudios Internacionales, Número 4, AEPDIRI, España. Disponible en: http://www.reei.org

Schmitter, Phillipe (1989), "Idealismo, Integración, Cambio de Régimen en el Cono Sur" en Revista Estudios Internacionales, Universidad de Chile, Sgto.

Soldatos, Panayottis y Michelman Hans (1996), Federalism and intrnationals relations: the role of subnationals units, Clarendosns Press, Québec.

Stahringer, Ofelia (2007), Integración y cooperación en el área de frontera. Bolivia, Argentina, Paraguay, Serie Integración Social y Fronteras Nº 3, CAB, Bogotá.

Strozzi, Susana (2002), Americanistas, latinoamericanistas y postcolonialistas, Centro de Estudios Latinoamericanos, Varsovia.

Tejeda, José Luis (2004), "La línea, la frontera y la modernidad" en Estudios Fronterizos, vol 5, № 10, junio-diciembre, México.

Todorov, Tzvetan(2003), La conquista de América. El problema del otro, FCE, México.

Tomassini, Luciano (1997), Felipe Herrera. Idealista y realizador, Fondo de Cultura Económica, Santiago. 
Vázquez, Luis (2003), «Construcción y deconstrucción de los pueblos indígenas bajo el nuevo espíritu del capitalismo» en Memoria $\mathrm{N}^{\circ} 170$.

Velasco, Juan Carlos (2006), «La noción republicana de ciudadanía y la diversidad cultural» en Revista ISEGORÍA $\mathrm{N}^{\circ} 33$.

Vieira Posada, Edgar (2005), "Evolución de las teorías sobre integración en el contexto de las teorías de relaciones internacionales" en Papel Político, Universidad Javeriana, $\mathrm{N}^{\circ} 18$.

Walsh, Catherine (2003), "Las geopolíticas del conocimiento y la colonialidad del poder Entrevista a Walter Mignolo" en Revista Polis, Vol. $1 \mathrm{~N}^{\circ}$ 4, Universidad Bolivariana, Santiago.

Idem (2006), Cruzando la raya, dinámicas socioeducativas e integración fronteriza. El caso de Ecuador con Colombia y Perú, Serie Integración Social y Fronteras No 2. CAB, Bogotá.

Wendt, Alexander (2005), "La Anarquía es lo que los Estados hacen de ella" en Revista Académica de Relaciones Internacionales, $\mathrm{N}^{\mathrm{o}} 1$, Año, Originalmente en: 1992. International Organization, Vol. 46, № 2.

Witker Barram, Iván (2004), "Mediterraneidad, soberanía y paradiplomacia: tres ejes de discusión teórica para la problemática chileno - boliviana" en Tapia, Marcela, Bolivia y Chile: Propuestas de Integración para el siglo XXI, Ediciones Instituto de Estudios Internacionales, Universidad Arturo Prat, Iquique.

Idem (2000), "Los Conceptos Interés Nacional y Regionalismo abierto en el acercamiento Chile/ MERCOSUR" en Politica y Estrategia. Santiago, ANPEE, Ministerio de Defensa. $\mathrm{N}^{\circ} 82$.

Zavala de Cosio, María (1997), "La frontera norte de México, singularidad demográfica y factores de cambio" en Las fronteras del Istmo. Fronteras y sociedades entre el sur de México y los países de América Central, Centro Francés de Estudios Mexicanos y Centroamericanos, México.

Zea, Leopoldo (2002) “La frontera en la globalización” en: Zea, L. y Taboada, H. (comp.) Frontera y globalización, FCE, México.

Idem (1992), "Integración, el gran desafío para Latinoamérica" en Patria Grande, Parlamento Latinoamericano, Argentina.

Zizek, Slavoj (1997), «Multiculturalismo o la lógica cultural del capitalismo multinacional» en: http://es.geocities.com/zizekencastellano/artMulticult.htm 